\title{
UNIVERSUM
}

I0.4067/So718-2376202100020066I

\section{¿QUIÉN ESTÁ DESTRUYENDO LA VIDA EN EL PLANETA? LA CONFRONTACIÓN DE LOS CONCEPTOS ANTROPOCENO Y CAPITALOCENO EN EL DEBATE AMBIENTAL ${ }^{\mathrm{r}}$}

\author{
Who is destroying life on the planet? The confrontation of the Anthropocene and Capitalocene \\ concepts in the environmental debate
}

\author{
Fernando Estenssoror ${ }^{1}$ (iD \\ 'Universidad de Santiago de Chile, Chile. fernando.estenssoro@usach.cl
}

\section{RESUMEN}

El artículo se inscribe en los estudios de las ideas y dimensión teórico-política del debate ambiental, entendiendo por este debate toda la discusión relativa a superar la crisis ambiental global. Al respecto, plantea la hipótesis que la crítica que el concepto Capitaloceno realiza al concepto de Antropoceno, tendería a estimular el debate teórico político acerca de la crisis ambiental global, que involucra responder preguntas tales como qué y quiénes serían sus principales sus responsables, cuándo y por qué comenzó, cómo se supera, resituando el debate en uno de los ejes de discusión teórico-políticos más importantes de la modernidad como será la tensión capitalismo-anticapitalismo. Para estos efectos, se exponen las tesis centrales de ambos conceptos que buscan responder las preguntas planteadas a fin de destacar su confrontación teórica.

PALABRAS CLAVE: Antropoceno ; Capitaloceno ; crisis ambiental global; debate ambiental; pensamiento político.

\section{ABSTRACT}

The paper is inscribed in studies of the ideas and theoretical-political dimension of the environmental debate, understanding by this debate all the discussion relative to overcoming the global environmental crisis. In this regard, it hypothesizes that the criticism that the Capitalocene concept realizes to the Anthropocene concept, would tend to stimulate the theoretical political debate about the global environmental crisis, which involves answering questions such as what and who would be responsible for it, when did it begin, how is it overcome, resituating the debate in one of the most important theoretical-political debates of modernity, such as the capitalism-anticapitalism tension. For these effects, the central theses of both concepts are exposed, which seek to answer the questions posed in order to highlight their theoretical confrontation.

KEYWORDS: Anthropocene; Capitalocene; global environmental crisis; environmental debate; political thought.

\footnotetext{
' Este artículo es producto del proyecto Fondecyt $\mathrm{N}^{\mathrm{o}}$ IIg048r: América Latina en la Geopolítica Ambiental Pos-Guerra Fría de los Estados Unidos. Antecedentes históricos y proyecciones (1989-2017).
} 
Fecha de Recepción 2020-08-05

\section{Fecha de Evaluación} 2020-09-30
Fecha de Aceptación

$2020-11-17$

\section{INTRODUCCIÓN}

Uno de los temas globales que hoy en día más ocupan a la comunidad científico-académica (entre otras) es la posibilidad de que el modo de vida contemporáneo esté destruyendo las bases ecosistémicas del planeta y el medio ambiente global, en una escala que puede ser irreversible y en extremo peligrosa. En otras palabras, estaría amenazado el propio proceso de vida en el planeta. Este grave problema o amenaza se ha denominado genéricamente Crisis Ambiental Global, ${ }^{2} \mathrm{y}$ fue puesto formalmente en la agenda pública mundial por la Organización de las Naciones Unidas (ONU), por medio de la conferencia mundial a que convocó sobre el estado del medio ambiente humano, celebrada en Estocolmo en 1972, Estocolmo '72. Recordemos que en el documento de convocatoria a este evento se señaló:

Se enfrenta una crisis ambiental global que pone en riesgo la vida del ser humano y del planeta [...] Nuestras bruscas y vastas aceleraciones -en el crecimiento demográfico, en el uso de la energía y de nuevos materiales, en la urbanización, en los ideales de consumo y en la contaminación resultante- han colocado al hombre tecnológico en la ruta que podía alterar, en forma peligrosa, y quizá irreversible, los sistemas naturales de su planeta, de los cuales depende su supervivencia biológica [...] En pocas palabras, los dos mundos del hombre -la biósfera de su herencia y la tecnosfera de su creación- se encuentran en desequilibrio y, en verdad, potencialmente, en profundo conflicto. Y el hombre se encuentra en medio. (Ward y Dubos, 1984, pp. 39 y 49)

Por este motivo, en el punto 7 de la declaración final de esta Conferencia, se llamó a todos los países, organizaciones e integrantes de la comunidad internacional a unir esfuerzos para terminar con esta grave amenaza:

7.- [...]hay un número cada vez mayor de problemas relativos al medio que, por ser de alcance regional o mundial o por repercutir en el ámbito internacional común, requerirán de una amplia colaboración entre las naciones y la adopción de medidas por las organizaciones internacionales en interés de todos. La Conferencia encarece a los gobiernos y a los pueblos a que aúnen sus esfuerzos para preservar y mejorar el medio humano en beneficio del hombre y de su posteridad. (Naciones Unidas, 1973, p. 4)

\footnotetext{
${ }^{2}$ Genéricamente la idea de crisis ambiental señala que ha sido el propio crecimiento económico, junto al elevado nivel de desarrollo y estándar de vida alcanzado por la Civilización Industrial (donde el Norte global, es su ejemplo arquetípico), el que ha generado problemas de carácter ecológico y ambientales de tan enorme magnitud, que por primera vez en la historia se ha puesto en riesgo la continuidad de la vida del ser humano en el planeta, así como el proceso de la vida del planeta mismo. En un primer momento las macro variables que componían esta crisis ambiental se referían a fenómenos tales como la contaminación, la pérdida de la biodiversidad, el calentamiento global o cambio climático, el agotamiento de los recursos, la destrucción de la capa de ozono, y la llamada, por algunos, 'explosión demográfica'. Posteriormente, y tras múltiples debates en el seno del sistema internacional, caracterizados por una clara confrontación Norte-Sur, se incorporaron otras variables y problemas generadores de esta crisis ambiental, tales como el tema de la pobreza y miseria en que vive gran parte de la humanidad (Estenssoro, 2020, p. 19-25).
} 
Desde esa fecha en adelante, se han realizado otras tres grandes cumbres y conferencias mundiales convocadas por la ONU a fin de evaluar el estado de medio ambiente global y definir nuevas tareas para enfrentar con éxito este desafío, además de un gran número de reuniones y conferencias realizadas para analizar por separado cada una de las grandes macro variables que componen la crisis ambiental. ${ }^{3}$

En este sentido, la importancia que ha adquirido el debate ambiental, entendido como toda la discusión teórico-política que se lleva adelante para superar la crisis ambiental global, ha sido enorme no sólo en el campo de la política internacional, sino también a nivel regional y local. E, igualmente se ha transformado en un tema muy estimulante para variados, prolíficos y multidisciplinares estudios en prácticamente todos los campos del conocimiento, por lo menos desde 1972 en adelante.

Entre los distintos aspectos que abarca el amplio debate teórico-político sobre esta crisis, es particularmente significativo el que se refiere a responder la pregunta: ¿quién o quienes la han generado o son sus principales responsables? Entre otras razones, porque desde un inicio la ONU señaló que esta crisis es de causas antropogénicas. O sea, se entiende que es el ser humano o, si se prefiere, la sociedad, quien la ha causado y, por tanto, será la sociedad la que deberá ponerse de acuerdo para resolverla, transformando este tema en un fenómeno político por definición. De hecho, los enormes esfuerzos por avanzar en las conferencias y cumbres mencionadas son un excelente ejemplo de cómo el sistema internacional busca desde hace casi 50 años alcanzar y perfeccionar acuerdos a fin de implementar políticas públicas globales tendientes a superar esta crisis, generando un impacto y retroalimentación de esta discusión a nivel multiescalar y multidimensional. Y, si bien han existido avances en varios aspectos, también hay retroceso y grandes desacuerdos. No son pocos los que opinan que, lamentablemente, el nivel de acuerdos necesarios para implementar políticas globales avanza más lento que la agudización de la crisis, como lo demuestra toda la discusión tendiente a mitigar la variable del cambio climático. ${ }^{4}$

\footnotetext{
3 Las grandes Cumbres y Conferencias convocadas por la ONU, siguiendo la dinámica de Estocolmo 72, son: la Conferencia de las Naciones Unidas sobre el Medio Ambiente y el Desarrollo, celebrada en Río de Janeiro en i992; la Cumbre Mundial sobre el Desarrollo Sostenible, celebrada en Johannesburgo en 2002; y la Conferencia de las Naciones Unidas sobre el Desarrollo Sostenible, nuevamente celebrada en Río de Janeiro en 2or2. Pero, además, la ONU, ha convocado a una gran cantidad de conferencias para tratar cada variable en particular que componen la crisis ambiental global, tales como la deforestación, el cambio climático, la pérdida de biodiversidad, la contaminación de las aguas, entre muchas otras (para profundizar en este aspecto ver el documento de Naciones Unidas, Principales cumbres y conferencias, disponible en: https://www.un.org).

${ }^{4}$ En la Conferencia de Río de Janeiro en 1992, se aprobó el texto de la Convención Marco de las Naciones Unidas Sobre el Cambio Climático (CMNUCC), con el objetivo de conseguir "la estabilización de las concentraciones de gases de efecto invernadero [GEI] en la atmósfera a un nivel que impida interferencias antropogenas peligrosas en el sistema climático"
} 
Al respecto, si concordamos en que es de causas antropogénicas, parte importante de la discusión política se orienta en torno a preguntas tales como: ies toda la humanidad, sin distinciones la responsable?; ¿todas las sociedades, sin importar sus características específicas y diferencias?; o sea ¿esta crisis fue y/o es generada por la especie humana, como tal?, o por el contrario, ¿es necesario diferenciar claramente respecto qué tipo de sociedad o sociedades la están causando?; o sea ¿quiénes (qué sociedades, grupos de interés, clases sociales, países) son los principales responsables y por lo tanto deben asumir su reparación?

Evidentemente, las respuestas a estas preguntas no son fáciles. Involucran una serie de complejos fenómenos que se relacionan, interactúan y configuran la discusión política, tales como visiones de mundo, tradiciones analíticas, proyecciones de sociedades deseables, intereses y relaciones de poder, entre otras. De aquí entonces, el análisis de este debate se ha transformado en un prolífico espacio de estudio político, tanto teórico y filosófico como práctico, ya que, según se respondan estas preguntas, se determinarán los énfasis, responsabilidades y características específicas de las acciones concretas tendientes a la superación de la crisis ambiental global.

En este sentido, en los últimos años viene desarrollándose un interesante debate respecto de cómo se debe entender el origen y los responsables de esta crisis. Específicamente, nos referimos al debate que ha surgido en torno del concepto de Antropoceno propuesto por Paul Crutzen y Eugene Stoermer (2000), que adquirió una gran repercusión y 'popularidad' (no sólo en la academia sino también en la sociedad civil), así como también ha provocado importantes críticas, vitalizando de esta forma el debate ambiental en general (entendido como el debate teórico político relativo a la superación de la crisis ambiental). En este sentido, una de las perspectivas críticas a las tesis planteadas por Crutzen y sus asociados con el concepto de Antropoceno, es la que propone Jason Moore con el concepto de Capitaloceno. Algunos de los aspectos principales de esta confrontación es la que pasamos a exponer.

\section{EL CONCEPTO DE ANTROPOCENO}

De acuerdo a lo señalado por el Grupo de Trabajo del Antropoceno (AWG según sus siglas en inglés), que pertenece a la Subcomisión de Estratigrafía Cuaternaria de la Unión Internacional de Ciencias Geológicas, el Antropoceno, o Edad del Humano, "es un término ampliamente utilizado

(Naciones Unidas, 1992, p. 4). Entre sus resultados, figuran el Protocolo de Kioto en 1997 y el Acuerdo de París 2015, destinados a reducciones globales de emisiones de GEI. Sin embargo, su implementación ha sido en extremo problemática, sobre todo por la oposición de Estados Unidos que se retiró del Protocolo de Kioto en 200I y en 2017 Donald Trump anunció el retiro de EE.UU. del Acuerdo de Paris 2015 (Estenssoro, 2019). 
desde que Paul Crutzen y Eugene Stoermer lo acuñaron en 2000 para denotar el intervalo de tiempo geológico actual, en el que muchas condiciones y procesos en la Tierra están profundamente alterados por el impacto humano", que se ha "intensificado significativamente desde el inicio de la industrialización, sacándonos del estado del Sistema de la Tierra típico de la Época del Holoceno que data de la última glaciación" (AWG, 2019).5

Efectivamente, en el año 2000 Paul Crutzen (ganador del Premio Nobel de química en 1995) y el biólogo Eugene Stormer, propusieron en la revista del Programa Internacional de la Geosfera y la Biosfera (IGBP), que la actividad humana había impactado tan profundamente al medio ambiente que se había trasformado en una fuerza geológica que estaba quedando grabada en la estratigrafía del planeta. ${ }^{6}$ Por lo tanto, ya no había que hablar de la actual época geológica como Holoceno, sino como Antropoceno:

Teniendo en cuenta estos y muchos otros impactos importantes y aún crecientes de las actividades humanas en la tierra y la atmósfera y, sobre todo, incluidas las escalas globales, nos parece más que apropiado enfatizar el papel central de la humanidad en geología y ecología al proponer el uso de término "Antropoceno" para la época geológica actual. (Crutzen y Stoermer, 200o, p. 17)

Vale decir, propusieron el concepto de Antropoceno...

... para capturar este cambio cuantitativo en la relación entre los humanos y el medio ambiente global. El término Antropoceno sugiere: (i) que la Tierra ahora se está moviendo de su época geológica actual, llamada Holoceno y (ii) que la actividad humana es en gran parte responsable de esta salida del Holoceno, es decir, que la humanidad se ha convertido en una fuerza geológica global por derecho propio. (Steffen et al., 20II, p. 843)

Y si bien los autores estaban conscientes de que la actividad humana vendría afectando el medio ambiente desde que prácticamente apareció sobre la faz del planeta, van a proponer como inicio del Antropoceno, los mediados del siglo XVIII que coincide con la revolución industrial, porque a partir de esa fecha "los efectos globales de las actividades humanas se han vuelto claramente perceptibles" (Crutzen y Stoermer, 2000, p. I8). Específicamente, fijan el inicio de Antropoceno entre mediados del siglo XVIII y las primeras décadas del siglo XIX, periodo de

\footnotetext{
5 Todas las traducciones son del autor.

${ }^{6}$ Entre los múltiples ejemplos que dan los autores sobre los impactos de la humanidad en el medioambiente planetario, señalan: "durante los últimos 3 siglos, la población humana aumentó diez veces a 6000 millones, [...] En unas pocas generaciones, la humanidad está agotando los combustibles fósiles que se generaron durante varios cientos de millones de años [...] la actividad humana ha incrementado la tasa de extinción de especies de mil a diez mil veces en las selvas tropicales y varios gases 'invernadero' climáticamente importantes han aumentado sustancialmente en la atmósfera [...] la humanidad libera muchas sustancias tóxicas en el medio ambiente e incluso algunas [...] han conducido al 'agujero de ozono' antártico [...] la depredación humana mecanizada ('pesca') elimina más del $25 \%$ de la producción primaria de los océanos en las regiones de afloramiento y el $35 \%$ en las regiones de la plataforma continental templada. Los efectos antropogénicos están bien ilustrados por la historia de las comunidades bióticas que dejan restos en los sedimentos lacustres..." (Crutzen y Stoermer, 2000, p. 17).
} 
tiempo que coincide con el inicio de la Revolución Industrial y la consiguiente revolución termoindustrial de la civilización occidental del siglo XIX con el uso masivo de combustibles fósiles.

La Revolución Industrial, con sus orígenes en Gran Bretaña en la década de ı7oo, o la revolución termoindustrial de la civilización occidental del siglo XIX, marcó el final de la agricultura como la actividad humana más dominante y puso a la especie en una trayectoria muy diferente del establecido durante la mayor parte del Holoceno [...] Es difícil establecer una fecha precisa de una transición que ocurrió en diferentes momentos y tasas en diferentes lugares, pero está claro que en I750, la Revolución Industrial apenas había comenzado, pero para I850 había transformado casi por completo a Inglaterra y se había extendido a muchos otros países de Europa y al otro lado del Atlántico hasta América del Norte. Por lo tanto, sugerimos que el año I8oo de podría elegirse razonablemente como el comienzo del Antropoceno. (Steffen et al., 20II, p. 847-849)

De igual modo, Steffen, Crutzen y McNeill (2007) van a proponer que la industrialización será una de las "tres o cuatro transiciones más decisivas en la historia de la humanidad", e incluso más, ya que potencialmente sería de "importancia similar en la historia de la Tierra misma" (p. 6r6). Y lo que hizo que la industrialización fuera tan central para el Sistema Tierra "fue la enorme expansión en el uso de combustibles fósiles, primero carbón y luego petróleo y también gas" (p. 6i6). Esto fue así porque los combustibles fósiles con sus tecnologías asociadas hicieron posibles muchas actividades nuevas e hicieron más eficientes a las antiguas, lo que va a trasformar drásticamente el medio ambiente planetario, con fenómenos tales como la desforestación y la conversión de la agricultura entre otros. Y la atmósfera estará entre los lugares del planeta donde la "transformación del medio ambiente a escala mundial por la industrialización", será más evidente (p. 6i6). Por ejemplo, si alrededor de 1850 , la concentración de $\mathrm{CO}_{2}$ en la atmósfera era de 285 ppm, se podía considerar que este era un rango de variabilidad natural para los períodos interglaciares durante el período del Cuaternario tardío. Sin embargo, durante el transcurso de I800/50 a 1945, la concentración de $\mathrm{CO}_{2}$ aumentó en aproximadamente 25 ppm, lo suficiente como para superar el límite superior de variación natural a través del Holoceno. Por estos motivos van a situar el inicio del Antropoceno, o su primera etapa, alrededor de i8oo, porque a partir de esas fechas se va a obtener "la primera evidencia indiscutible de que las actividades humanas estaban afectando el medio ambiente a escala global" (p. 616).

También, van a proponer que existe una segunda etapa del Antropoceno que comienza en I945, tras el fin de la Segunda Guerra Mundial, y que se caracterizaría por un drástico aceleramiento del impacto humano sobre el medio ambiente global. En sus palabras, se habría producido una "Gran Aceleración" de este impacto, reflejada en fenómenos tales como, "la población se duplicó en solo 50 años, a más de 6 mil millones para fines del siglo XX", y las concentraciones atmosféricas de varios gases de efecto invernadero "han aumentado sustancialmente, y la Tierra se está calentando rápidamente”, entre otros efectos (Steffen, Crutzen 
y McNeill, 2007, p. 617). O sea, desde "los últimos 50 años, los humanos han cambiado los ecosistemas del mundo de manera más rápida y extensa que en cualquier otro período comparable en la historia humana" y el planeta "está en su sexto gran evento de extinción, con tasas de pérdida de especies que crecen rápidamente tanto para los ecosistemas terrestres como para los marinos". De aquí entonces, "la notable explosión de la empresa humana desde mediados del siglo XX, y los impactos asociados a escala global" sobre el "funcionamiento del Sistema Tierra marcan la segunda etapa del Antropoceno: la Gran Aceleración” (Steffen, Crutzen y McNeill, 2007, p. 6r7).

Y esta situación de transformación del Sistema Tierra por el ser humano, no va a cambiar en el futuro, sino que continuará acentuándose, a menos que ocurra algún evento catastrófico (una guerra nuclear, el impacto de un gran asteroide, otros). Por lo tanto, Crutzen y Stoermer (2000) van a plantear que la humanidad "seguirá siendo una fuerza geológica importante durante muchos milenios, quizás millones de años por venir" (p.I8). Y esta es la razón más importante para "desarrollar una estrategia mundialmente aceptada que conduzca a la sostenibilidad de los ecosistemas contra las tensiones inducidas por los humanos", en donde el papel de "la comunidad global de investigación e ingeniería", será clave "para guiar a la humanidad hacia una gestión ambiental global y sostenible" (p. i8). Por lo tanto, como bien dice Ellis, para Crutzen, la geoingeniería y el Antropoceno son dos conceptos profundamente entrelazados (Ellis, 2018). Y, en este sentido, se ha señalado que el concepto de geoingeniería, o sea "manipular el clima a propósito para contrarrestar el calentamiento global" es "una de las extensiones más radicales de la idea" de Antropoceno planteada por Crutzen y sus asociados (Kintisch, 2013). Como el propio Crutzen planteó en 2002:

... como uno de los rasgos característicos del antropoceno, las distantes generaciones futuras de 'homo sapiens' harán todo lo posible para evitar que se desarrolle una nueva era de hielo agregando poderosos gases de efecto invernadero artificiales a la atmósfera. De manera similar, cualquier caída en los niveles de $\mathrm{CO}_{2}$ a concentraciones demasiado bajas, que conduzca a reducciones en la fotosíntesis y la productividad agrícola, sería combatida por las emisiones artificiales de $\mathrm{CO}_{2}$. (citado en Ellis, 2018, p. 151)

De hecho, un importante número de científicos partidarios del concepto de Antropoceno, incluido Crutzen, solicitaron en 2006, que se hicieran "investigaciones preliminares de técnicas de geoingeniería, como usar partículas de azufre para reflejar parte de la luz del sol de vuelta al espacio" (Kintisch, 2013). Y, lo cierto es que de la mano del Antropoceno la geoingeniería también se está discutiendo profusamente, especialmente en los países desarrollados, no solo a nivel científico, sino ya en el espacio de tomadores de decisiones y responsables de políticas, 
particularmente en aspectos que tienen que ver con la gobernanza climática global (Huttunen, Skytén y Hildén, 2015).

Posteriormente a la propuesta de Antropoceno de Crutzen y Stoermer, el geólogo Jan Zalasiewicz, de la Universidad de Leicester en Inglaterra, con un grupo de sus colegas, señalaron que el concepto de Antropoceno efectivamente era el más apropiado para definir la edad contemporánea, dado que existía "evidencia suficiente de un cambio estratigráficamente significativo (tanto transcurrido como inminente) para el reconocimiento del Antropoceno" (Zalasiewicz, 2008, p. 7). Por esta razón y debido a que el concepto de Antropoceno no estaba reconocido formalmente por la Unión Internacional de Ciencias Geológicas, al año siguiente, en 2009, la Sub Comisión de Estratigrafía Cuaternaria, perteneciente a la Comisión Internacional de Estratigrafía (ICS según sus siglas en inglés), recomendó a Jan Zalasiewics, para formar el Grupo de Trabajo de Antropoceno (AWG), con la tarea de examinar y reconocer un nuevo intervalo de tiempo geológico basado en "los efectos de gran alcance de las influencias antropogénicas en los parámetros estratigráficamente significativos" (Ellis, 20I8, p. 48). O sea, encontrar la evidencia científica para identificar la Edad del Antropoceno, o Edad de los Humanos, en la escala de tiempo geológico.

Sin embargo, más allá del fallo definitivo de los geólogos, lo cierto es que desde que fuera propuesto por primera vez en el 2000, el concepto de Antropoceno ha tenido un impacto enorme, no sólo en el debate ambiental y en las ciencias de la vida, sino también en las ciencias sociales, humanidades y artes, así como a nivel de la sociedad civil.

Según Manrique, el neologismo Antropoceno ganó "legitimidad científica y académica en un tiempo récord", pero además ha trascendido mucho más allá de la comunidad científica. Por ejemplo, los museos de la Smithsonian Institution de Washington DC, modificaron sus exposiciones permanentes en función de este concepto (Manrique, 2015, p. 173). Por estos motivos, se plantea que "en dos décadas desde que Crutzen lo propuso por primera vez, el Antropoceno ha inspirado un aluvión de preguntas socialmente relevantes, avivó debates intensos y sirvió como musa para artistas y diseñadores" (Ellis, 20I8, p. I28). En otras palabras, "la discusión acerca de la "época de los seres humanos' se ha expandido más allá de las ciencias biológicas y geológicas", para convertirse en parte de la "cultura popular" (Thrischler, 20I7, pp. 4I-42). Incluso los críticos de este concepto reconocen que su gran mérito consiste en que ha conseguido estimular "un diálogo público y académico que ha puesto en conversación a artistas, críticos culturales, economistas políticos, 
historiadores, geógrafos, biólogos y muchos otros", sobre un tema que es muy importante en nuestra época, como es el tema del "cambio climático y extinción masiva" (Moore, 2017b, p. 598).

Sin embargo, el éxito que ha tenido este concepto de Antropoceno, no significa que exista una sola forma de entenderlo, o que los planteamientos de Crutzen sean unánimemente aceptados por a la comunidad científica. Por el contrario, existen importantes análisis críticos sobre este concepto, así como distintos énfasis en su comprensión. Según Lewis y Maslim (2018), si bien en la actualidad "es difícil encontrar un científico que no esté de acuerdo con la afirmación central del Antropoceno: que las acciones humanas han cambiado radicalmente la Tierra como un sistema integrado" (p. 269), esto no significa la inexistencia, tras casi 20 años de enriquecedor debate, de importantes discrepancias respecto a la definición original que propuso Crutzen, o que no carezca de gran complejidad fijar el inicio de esta época geológica del Humano. En otras palabras, aceptando la idea central que propone el Antropoceno, no es un tema menor cómo se responde a preguntas sobre, quién lo origina y cuándo se origina, dado que estas respuestas tendrán importantes derivaciones políticas, razón por la cual "la historia que elegimos contar importa" (p. 7). Por ejemplo, existe una perspectiva que señala que "el Antropoceno comenzó cuando la gente empezó a utilizar el fuego o la agricultura, el cambio ambiental es simplemente parte de la condición humana" y, por lo tanto, este criterio puede utilizarse para "normalizar y restar importancia al cambio ambiental global actual" (pp. 7 y i2). Por el contrario, otras perspectivas señalan que "la actividad humana transformó la Tierra solo en las últimas décadas", y esto significa que "debemos cuestionar el papel de la tecnología y el desarrollo del capitalismo de consumo" (p. 8). O sea, según se respondan estas preguntas y otras similares, se pueden llegar a resultados políticos muy distintos. De aquí entonces, surge la gran interrogante sobre “iquién tomará la monumental decisión de arbitrar cuando las acciones humanas constituyen una fuerza de la naturaleza?" (p. I2). Y, por el momento, la respuesta a esta interrogante "está a cargo de una red de comités poco conocida, que decidirá si el Antropoceno se convertirá en parte de la historia geológica oficial de la Tierra, conocida como Escala de Tiempo Geológico" y, hasta el presente "sus deliberaciones han sido tensas y sin consenso, con una decisión oficial que no se espera hasta dentro de muchos años" (p. I2).

Por lo tanto, se debe tener presente la existencia de distintas lecturas e interpretaciones respecto de este concepto. Por ejemplo, Christophe Bonneuil y Jean-Baptiste Fressoz van a plantear que existe una historia oficial y dominante del Antropoceno, muy conveniente a los intereses de 
poder de los centros hegemónicos del Norte global y sus grandes conglomerados del capitalismo transnacional:

... los centros de gobierno del mundo han sido durante mucho tiempo los lugares donde se ha hablado y demostrado lo que equilibra o desequilibra el planeta. Construyen esferas en las que se presentan las formas adecuadas de manejarlo, templarlo o aclimatarlo: desde los invernaderos del Jardin du Roi donde Buffon escribió sus Épocas de la Naturaleza hasta los proyectos de geoingeniería impulsados por Paul Crutzen. (Bonneuil y Fressoz, 2016)

Por lo tanto, existen razones para sospechar "que el conocimiento y el discurso del Antropoceno pueden formar parte, tal vez sin saberlo, de un sistema hegemónico para representar el mundo como una totalidad a gobernar" (Bonneuil y Fressoz, 2016). Por esto es importante someter a critica las narrativas del Antropoceno, lo que no significa negar "el valor de las investigaciones de estos antropocenólogos", sino que, por el contrario, "se trata más bien de abrir a la discusión la narrativa oficial del Antropoceno, para permitir una reflexión más profunda sobre las particularidades de nuestras representaciones del mundo", porque si no se hace este ejercicio "el seductor concepto Antropoceno bien podría convertirse en la filosofía oficial de un nuevo geopoder tecnocrático y orientado al mercado" (Bonneuil y Fressoz, 2016). En este sentido, los autores critican lo que denominan la narrativa oficial del Antropoceno -la de Paul Crutzen y sus asociados-, porque culpa a toda la humanidad, sin distinciones, de la situación ambiental y ecológicamente critica en la que nos encontramos. Se escriben libros enteros sobre el Antropoceno "sin siquiera mencionar el capitalismo, la guerra, los Estados Unidos, o el nombre de una gran corporación", a pesar de que "noventa corporaciones son responsables del 63 por ciento de las emisiones acumuladas de dióxido de carbono y metano entre i850 y hoy" (Bonneuil y Fressoz, 20i6). O sea, "la narrativa dominante de los antropocenólogos del Antropoceno presenta una humanidad abstracta uniformemente involucrada y, lo que implica, uniformemente culpable" (Bonneuil y Fressoz, 2016). Esto significa que un miembro de la cultura Yanomani de la Amazonía es igualmente responsable de la crisis ambiental que el dueño de una gran transnacional, dado que ambos pertenecen al Anthropos. Pero esto es una falacia para Bonneuil y Fressoz, quienes, al respecto, plantean:

Las ochenta personas más ricas del mundo tienen un ingreso combinado superior al de los $4 \mathrm{I} 6$ millones más pobres, jcada uno gana más de un millón de veces el de sus semejantes! Esta ampliación de las desigualdades es una fuente importante de desorden ecológico global, ya que los individuos más ricos establecen un estándar de consumo que aquellos que están por debajo de ellos buscan igualar. (Bonneuil y Fressoz, 2016) 
En este sentido, sugieren que en vez de Antropoceno "sería mejor utilizar el término de Erik Swyngedouw 'Oliganthropocene', una época geológica causada por una pequeña fracción de la humanidad" (Bonneuil y Fressoz, 2016).

De igual forma, la misma perspectiva crítica que existe frente al concepto de Antropoceno también existe frente al concepto de geoingeniería. Por ejemplo, Bruno Latour (2017) va a señalar que la idea de geoingeniería hunde sus raíces en la tradicional ambición moderna de controlar la naturaleza, sólo que ahora, ante la gravedad de la crisis ambiental, sus defensores reaccionan con pánico y caen en un frenesí megalómano de control total del planeta, para lo cual proponen entender el sistema terrestre como "una gran máquina que ha dejado de funcionar correctamente solo porque no la hemos controlado de manera suficiente", por lo tanto se debe corregir este error y dominar a esta naturaleza "recalcitrante y salvaje", recurriendo al "gran delirio que llaman, modestamente, geoingeniería" (p. I2). De esta manera, si la crisis ambiental los lleva a preguntarse, “ila modernización nos ha llevado a un callejón sin salida?", entonces responden como solución: "¡Seamos aún más decididamente modernos!" (p. I2). Y, lo peligroso de esta actitud megalómana es que, si no se controla, finalmente, el tradicional sueño moderno de pretender controlar la naturaleza se termine transformando en la "pesadilla de la geoingeniería" (p. 282).

\section{EL CONCEPTO DE CAPITALOCENO}

Entre las perspectivas críticas al concepto de Antropoceno según lo formuló Crutzen, está el concepto de Capitaloceno planteado por Jason W. Moore (de la Universidad de Binghamton, Nueva York). Su crítica se puede sintetizar en dos grandes aspectos. Por una parte, rechaza que se catalogue genéricamente a la crisis ambiental como una crisis de carácter antropogénica, en el sentido que hace recaer la responsabilidad de su generación en el conjunto de la humanidad sin mayores distinciones y, por otra parte, rechaza que se situé el origen de la crisis ecológica y/o ambiental en los inicios la revolución industrial (mediados del siglo XVIII en adelante). Por el contrario, Moore va a defender la tesis que esta crisis ambiental comenzó con los inicios del capitalismo de la era moderna (I450 en adelante) y, consecuentemente, fue generada por el modo de producción capitalista y los sectores de la sociedad que más se han beneficiado con éste.

Como explica Moore (201za), fue cuando escribió Naturaleza y Transición, ${ }^{7}$ a fin de entender la creciente crisis ecológica del siglo XXI, el momento en que tomó conciencia de que la

\footnotetext{
7 Moore se refiere a su artículo Nature and the Transition from Feudalism to Capitalism, publicado en el 2003 en la Revista del centro Fernand Braudel de la Universidad de Bighampotn.
} 
crisis ambiental era la consecuencia de dos crisis que ocurren al interior del sistema capitalista: una crisis económica y una crisis ecológica. Ahí, descubrió que la crisis ecológica sería inherente a la lógica de acumulación interminable del capitalismo:

Como comprendí en ese momento, había dos contradicciones básicas hoy en juego en el capitalismo: una tendencia a la crisis "económica" y otra a la crisis "ecológica". Si bien la crisis económica es dirigida por la tendencia hacia la sobreacumulación de capital, la crisis ecológica es impulsada por la tendencia a apropiarse sin límite de los "frutos gratuitos" de la naturaleza [...] Llegué a ver que lo que aparecía como dos movimientos separados -transformaciones del capital y transformaciones de la Tierra- eran en realidad uno: la acumulación del capital es la transformación de la naturaleza. (Moore, 20I3a, p. I2)

Por cierto, no desconoce que históricamente los seres humanos han intervenido su medio ambiente natural causando diferentes niveles de degradación, al señalar que los "humanos, como todas las especies, somos productos y productores de nuestro medioambiente simultáneamente" (Moore, 2016, p. I45). De la misma forma, coincide que en la actualidad la gravedad del problema radica en la escala global de degradación que se ha alcanzado, motivo por el cual el debate ambiental gira en torno a la "idea de crisis ecológica como crisis ecológica absoluta", o "desastre ecológico planetario" (Moore, 20r3b, p. 35). Sin embargo, lo distintivo para él es que esta degradación global, comenzó con "el surgimiento del capitalismo en el 'largo' siglo XVI (c. I450I640)", por lo tanto, fue el capitalismo lo que "marcó un punto de inflexión en la historia de la relación de la humanidad con el resto de la Naturaleza" (Moore, zorza, p. го).

Este fenómeno lo explica recogiendo el planteamiento de Marx, al señalar que "todas las civilizaciones tienen leyes de valor, prioridades ampliamente modeladas para lo que es valioso y lo que no lo es", y el capitalismo se va a caracterizar porque "el valor pasó de la productividad de la tierra en condiciones de poder señorial a la productividad laboral bajo la hegemonía del mercado mundial moderno, 'la base misma y la atmósfera viva del modo capitalista' de producción" (Moore, 20r6, p. 98). Esto va a significar que, bajo el capitalismo, todo en la Naturaleza se "puso al servicio de la productividad laboral" y se trasformó en mercancías destinadas a ser intercambiadas en el mercado, buscando la acumulación sin fin del capital (Moore, 2016, p. 9I). Y cuando se habla de todo en la naturaleza, se debe entender tanto a la naturaleza humana como a la naturaleza extrahumana. ${ }^{8}$ Por este motivo, el capitalismo debe ser entendido como un sistema que, bajo el objetivo de la acumulación permanente del capital, implica "un patrón emergente de innovación simbólica y

\footnotetext{
${ }^{8}$ Moore (2016) rechaza la dualidad cartesiana propia de la época moderna e ilustrada, que separa el ser humano de la naturaleza. Para él, el ser humano es naturaleza, por eso prefiere hablar de naturaleza y naturaleza extra-humana, donde naturaleza (con minúscula) son los seres humanos y la naturaleza extra-humana, es la naturaleza no humana y ambas naturalezas conforman la red de la vida. De igual forma, plantea que el capitalismo transforma a la naturaleza y la naturaleza extra-humana en mercancías, o sea Naturaleza con mayúsculas.
} 
transformación material en el que el valor de la fuerza de trabajo, el surgimiento del dinero mundial y la transformación sin fin de la tierra forman un todo histórico en evolución" y este todo histórico o sistema capitalista, Moore lo denomina Ecología-Mundo capitalista (Moore, 2016, p. II $)$.

Esta Ecología-Mundo, primero comenzó en Europa y prontamente se centró en el mundo atlántico, para, finalmente, expandirse a una escala global, lo que significó que en "los tres siglos posteriores a I450, se produjo la mayor revolución paisajística en la historia humana. [...] en tres sentidos: velocidad, escala y alcance" (Moore, 20r6, p. 9o). Por lo tanto, se puede considerar que "el surgimiento del capitalismo después de 1450 marcó un punto de inflexión en la historia de la relación de la humanidad con el resto de la naturaleza" y fue un fenómeno "mayor que cualquier línea divisoria desde el surgimiento de la agricultura y las primeras ciudades [...] fue incluso mayor que el auge de la máquina de vapor" (Moore, 2016, p. 96).

Entre los múltiples impactos de esta ecología-mundo capitalista, estará el haber provocado la mayor degradación ecológica del planeta, hasta desembocar en la actual crisis ambiental global. Por ejemplo, si la Europa feudal "había tardado siglos en deforestar grandes extensiones de Europa occidental y central", con el auge del capitalismo temprano o capitalismo mercantil, después de I450, "se produjo una deforestación comparable en décadas, no siglos", entre otras razones porque el nuevo capitalismo metalúrgico de Europa central "recorrió el campo en busca de combustible, provocando una contaminación y deforestación generalizadas" (Moore, 2016, pp. 96 y I04). Otro buen ejemplo, entre los múltiples que entrega Moore, ${ }^{9}$ es lo que ocurrió con el auge del azúcar, "el cultivo comercial original de la modernidad" que no solo "devoraba bosques y suelos agotados", sino que también "era un aparato de matanza masiva en forma de esclavitud africana" (Moore, 20r6, p. I05). En la isla de Madeira frente a las costas africanas, donde se inició el auge de este cultivo, así como del trabajo esclavo africano, entre I470 y I5ı, se arrasó con la mitad de su masa boscosa. De igual forma, para 1570 en el nordeste del Brasil, que se había convertido en el principal centro azucarero del mundo, este cultivo impulsó "la primera gran ola de desbroce de la selva tropical atlántica" (Moore, 2016, p. I05). Para I650 las demandas de leña requeridas para la producción de azúcar habían implicado "la tala de unos 5.ooo kilómetros cuadrados de bosque", además de la llegada de cerca "240,00o esclavos africanos" al Brasil (Moore, 2016, p. I05). En este sentido, dice

\footnotetext{
9 Moore, refiriéndose al capitalismo mercantil, identifica 23 grandes hitos históricos que significaron un importante nivel degradación del medio ambiente y transformación de la naturaleza desde inicios del siglo XVI hasta el inicio de la Revolución Industrial, y que van desde la "revolución agrícola de los Países Bajos (c. I400-160o)", hasta "el "intercambio colombino’ que hizo historia, al fluir las enfermedades del Viejo Mundo hacia el Nuevo Mundo, y los cultivos del Nuevo Mundo fluyeron al Viejo, como lo fueron la papa y el maíz" (Moore, 20I3 a, pp. Io y iI).
} 
Moore, el capitalismo utilizó el trabajo humano como simple mercancía y siempre tratando de obtener esta mercancía al más bajo precio posible, ya sea en calidad de trabajo esclavo o pagando salarios miserables y, en este proceso el capitalismo excluyó "a la mayoría de los humanos de la humanidad: pueblos indígenas, africanos esclavizados, casi todas las mujeres e incluso muchos hombres de piel blanca" (Moore, 2016, p. 79).

Además, según Moore, la racionalidad del capitalismo requerirá de la constante expansión del espacio geográfico bajo su dominio, impulsando a los europeos a la conquista y colonización de nuevos territorios y seres humanos desde a segunda mitad del siglo XV en adelante por lo que, la "acumulación interminable de capital y la apropiación interminable de la Tierra forman un proceso histórico-mundial singular" (Moore, 201za, p. I8). Esto es así, debido a que el capitalismo requiere, para su permanentemente proceso de acumulación, apropiarse de lo que Moore llama la naturaleza barata o Four Cheaps: trabajo, comida, energía y materias primas (Moore, 2013a, 2017a, 2017b). O sea, el capitalismo requiere apropiarse de los recursos naturales que se han formado por cientos de miles de años por el 'trabajo' de la naturaleza (suelos, madera, minerales, fuentes energéticas, otros), sin pagar por este 'trabajo' natural, además de apropiarse del trabajo humano. Mientras más baratos sean estos Four Cheaps, mayor será el excedente posible de ser apropiado y acumulado por los capitalistas. Pero, en la medida que en un determinado espacio geográfico la propia explotación capitalista va agotando los Four Cheaps -agotamiento que incluye la degradación ambiental-, estos comienzan a encarecerse, lo que va a influir negativamente en el proceso de acumulación del capital, motivo por el cual los capitalistas se expandirán hacia otros espacios geográficos buscando siempre Naturaleza barata (Moore, 2013a, 2017a, 2017b).

Bajo esta lógica, desde I45o en adelante el capitalismo europeo, por medio de la conquista y la colonización, estará expandiendo sus fronteras, primero África y el Nuevo Mundo hasta abarcar el planeta completo, y cada acto de expansión de fronteras significará todo un ciclo de crecimiento y acumulación capitalista. Como dice Moore, "ese proceso de conseguir naturalezas extra-humanas -y humanas también- para trabajar por costes mínimos de dinero y energía es la historia de las grandes fronteras mercantiles del capitalismo y, con ello, de las largas olas de acumulación capitalista" (Moore, 2017a, p. I69). Estos movimientos de fronteras incorporaron "no solo vastas extensiones de Naturaleza potencialmente barata, sino también la fuerza de trabajo para activarla" (Moore, 2016, p. IO2). De esta forma, el capitalismo "movilizó el trabajo no remunerado y la energía de los humanos", así como a la naturaleza extra-humana, transformando el paisaje y el medio 
ambiente a una escala sin precedentes en la historia, motivado por "un propósito singular: la acumulación interminable de capital" (Moore, 2016, p. 79).

Y, como se ha señalado, en este proceso también fue degradando el ambiente hasta provocar la actual crisis ambiental. Por cierto, esto fue un proceso gradualmente creciente. En los primeros siglos, el genio del capitalismo estuvo "en evitar los costos de la degradación ecológica local y regional mediante la reubicación" (Moore, 2013b, p. 35), por lo tanto, las crisis ecológicas regionales, como la sucedida en la isla Madeira por el auge del azúcar, "no plantearon obstáculos insuperables a la acumulación" e históricamente, "las crisis ecológicas locales pudieron ser superadas mediante la extensión global de las actividades productivas" (Moore, 2013b, p. 35). Sin embargo, como el capitalismo implica un proceso de explotación de la naturaleza barata en una escala siempre creciente, va a llegar a un punto en que ya no le será posible seguir expandiéndose una vez que haya alcanzado una escala de degradación ecológica global. Esto ocurrirá, en la segunda mitad del siglo XX, después de la $2^{\underline{a}}$ Guerra Mundial, cuando a raíz del enorme aumento de la actividad económico-industrial y de la expansión de la sociedad del consumo, "por primera vez, las contradicciones ecológicas del capitalismo comenzaron a jugar en una escala que correspondía a sus actividades económicas", sea, los "procesos económicos del capitalismo comenzaron a rivalizar con los ciclos ecológicos del planeta", lo que significará que la economía-mundo capitalista abrió la posibilidad de un desastre ecológico a escala planetaria (Moore, 2013b, p. 35).

Por lo tanto, para Moore la crisis ambiental global fue producto de la nueva ley del valor del capitalismo, que pasó de la productividad de la tierra a la productividad laboral. Esta ley "reconfiguró la naturaleza, humana y extra-humana -esclavos, bosques, suelos- no mercantilizada al servicio de la productividad y la mercantilización", y además impulsó la creciente necesidad del capital de apropiarse la naturaleza barata (Moore, 2017a, p. I44). Esto significa que la "actual perturbación de la biosfera se encuentra a lo largo del siglo XVI" (Moore, 2017a, p. I45), y no en la revolución industrial como propone el Antropoceno. El paso del capitalismo mercantil al capitalismo industrial, con la revolución industrial y el uso de los combustibles fósiles, sólo responde a la secuencia lógica de la racionalidad del capitalismo: la acumulación sin fin del capital. Esto significa, por una parte, que la crisis ambiental no es un problema técnico o energético, sino que es producto de la lógica inherente que explica al capitalismo y, por otra parte, la grave perturbación ecológica y ambiental que enfrentamos no fue generada por el Anthropos, que asume a la humanidad como un todo indiferenciado, sino que "a lo que estamos asistiendo es al 'fin de la naturaleza barata' como una estrategia civilizatoria, nacida durante el auge del capitalismo en el 
'largo' siglo XVI (I450-I648)" por lo tanto, nuestro "problema no es el antropoceno, sino el capitaloceno" (Moore, 2017a, p. 145).

Por todos estos motivos, para Moore los defensores del Antropoceno defienden "un concepto fundamentalmente burgués", especialmente "por su eliminación de la especificidad histórica del capitalismo y la consiguiente implicación de que las contradicciones socioecológicas del capitalismo son responsabilidad de todos los humanos" (Moore, 20I6, p. 83). Y, al hacer recaer los orígenes de la actual crisis ambiental en la Gran Bretaña de alrededor del i8oo y culpar de este proceso al Anthropos, lo que hacen, finalmente, es limpiar la imagen del capitalismo, diluyendo y ocultando sus contradicciones socioecológicas. Esto es "un truco tan antiguo como la modernidad: los ricos y poderosos crean problemas para todos nosotros, luego nos dicen que todos tenemos la culpa" (Moore, 2017b, p. 599).

En síntesis, para este autor, los grandes y serios problemas que enfrentamos en la actualidad a nivel global son todos resultados de "un único proyecto civilizatorio: la ecologíamundo capitalista" (Moore, 2017a, p. I49). Esto significa que la crisis ambiental, no es producto "de una humanidad 'abrumando las grandiosas fuerzas de la naturaleza', sino más bien la de un capitalismo agotando su estrategia de naturaleza barata" (Moore, 20I7a, p. I69). Y el mejor ejemplo es el del cambio climático, ya que "es una certeza creciente que el calentamiento global constituye una barrera insuperable para cualquier revolución agrícola nueva $-\mathrm{y}$, con ello, para cualquier regreso de la comida barata-" (Moore, 20I7a, p. I70). De aquí entonces, la crisis ambiental no se va a superar evolucionando hacia una economía capitalista verde o depositando la fe en la geoingeniería según proponen, usando las categorías de Bonneuil y Fressoz (2016), los defensores de "la narrativa oficial del Antropoceno", como por ejemplo es el caso del Breakthrough Institute, uno de los mayores "defensores de ese capitalismo verde que confía en soluciones centralizadas, capaces de implementar ambiciosos proyectos de tecnoingeniería a cargo del gran capital [...] enraizados en la Big Science: fraccionamiento hidráulico de rocas para la obtención de combustible fósil [...] geoingeniería ambiental" y otras medidas similares (Danowski y Viveiros de Castro, 2019, pp. 9596), sino que, por el contrario, la crisis solo se supera terminando con la lógica de la ecologíamundo capitalista que, en su propósito de acumulación sin fin, ha llegado a su límite, o mejor dicho ha creado su propio límite, al agotar su estrategia de apropiación de naturaleza barata. 


\section{REFLEXIONES FINALES}

Sin duda el neologismo de Antropoceno ha tenido una gran aceptación e impacto no sólo a nivel de la academia, sino, también, en la sociedad civil, estimulando y socializando aún más el debate sobre la necesidad de superar la crisis ambiental global. Sin embargo, este fenómeno ha ocurrido particularmente en el Norte global, no así en Latinoamérica donde su debate ha sido menor y más tardío como bien expuso Virginia García (2017), al señalar que "la mayor parte de esa bibliografía y de las reflexiones está en inglés. Es del Norte y para el Norte, con muy pocas excepciones" (p. I4). García realiza este planteamiento buscando incentivar el diálogo en torno al Antropoceno en América Latina, con críticas y aportaciones, entendido como alimento y "combustible para el pensamiento" también desde el Sur (p. I4). Estas reflexiones de García, las podemos hacer extensivas al neologismo Capitaloceno, que presenta un interesante desarrollo principalmente en las corrientes de pensamiento crítico del Norte global (Crist, 20r6; Haraway, 20ı6; McBrien, 20r6; Altvater, 20I4, 20I6; Hartley, 20ı6; Parenti, 20I6; Abelda, 20I9; Sánchez, 20I9; Alvater y Mahnkopf, 2019). E, igualmente, también ha comenzado a estimular el debate en América Latina (Caña, 2017; Ulloa, 2017; Escalera, Ángeles y Palafox, 2017; Barcelos, 2019).

Pero, por cierto, es importante que reflexiones como las que hace Virginia García, se realicen tomando en consideración que existe una riquísima tradición teórico política y de ecología política en América Latina, a lo menos, desde Estocolmo 72 en adelante. ${ }^{\text {Io }}$ En este sentido, el debate en torno al Antropoceno, así como las críticas al carácter depredador del capitalismo que profundiza Moore, se pueden estudiar de manera dialógica con el pensamiento latinoamericano sobre la crisis ambiental global. Por ejemplo, pensemos en el análisis sobre el Antropoceno en clave latinoamericana, que propone Maristella Svampa cuando relaciona la idea de Antropoceno con la expansión de la frontera de los commodities en la periferia bajo el fenómeno del neoextractivismo (Svampa, 2019). Con este espíritu, se enfrentó el presente trabajo buscando entregar antecedentes que permitan seguir profundizando en un debate que tiene larga data en esta región del mundo.

\section{REFERENCIAS}

Abelda Raga, José Luis (2019). La belleza circular: Una aproximación a la estética de la sustentabilidad para el Capitaloceno. Arte y Políticas de Identidad, 20, I4-28.

\footnotetext{
ro Para profundizar en los primeros aportes del pensamiento latinoamericano al debate ambiental ver: Fernando Estenssoro (2020), Historia del debate Ambiental en la Política Mundial. 1945-1992. La perspectiva latinoamericana.
} 
Altvater, Elmar (2014). El Capital y el Capitaloceno. Mundo Siglo XXI, 9(33), 5-15.

Altvater, Elmar (2016). The capitalocene, or, Geoengineering against Capitalism's Planetary Boundaries". En Moore, Jason W. (Ed.), Anthropocene or Capitalocene? Nature, History and the Crisis of Capitalism (pp. I38-152). Kairos-PM Press.

Altvater, Elmar y Mahnkopf, Birgit (2018). The Capitalocene: Permanent Capitalist CounterRevolution. En Panitch, Leo y Albo, Greg (Eds.), The World Turned Upside Down?. Socialist Register 2019 (pp. 79-89). NYU Press.

AWG (2019). What is the Anthropocene? - current definition and status. AWG. hetps://cutt.ly/ZTpWCZM

Barcelos, Eduardo Álvares da Silva (2019). Antropoceno ou Capitaloceno: Da simples disputa semântica à interpretação histórica da crise ecológica global. Revista Iberoamericana de Economía Ecológica, 3i(I), I-I7.

Bonneuil, Christophe y Fressoz, Jean-Baptiste (2016); The Shock of the Anthropocene. The Earth, History and Us [e-book]. Verso.

Caña Jiménez, María del Carmen (2017). Violencia, necropolítica y capitalocene en "Cromo". Revista Canadiense de Estudios Hispánicos, Vol. 42(I), I-23.

Naciones Unidas (1992). Convención Marco de las Naciones Unidas sobre el Cambio Climático. Naciones Unidas. https://cutt.ly/mTpW043.

Crist, Eileen (2016). On the Poverty of Our Nomenclature. En Moore, Jason W. (Ed.), Anthropocene or Capitalocene? Nature, History and the Crisis of Capitalism (pp. 14-33). Kairos-PM Press.

Crutzen, Paul J. y Stoermer, Eugene F. (2000). The 'Anthropocene'. IGBP News Letter, 4I I7-I8.

Danowski, Déborah y Viveiros de Castro, Eduardo (2019). ¿Hay Un Mundo Por Venir? Ensayo sobre los miedos y los fines. Caja Negra Editora.

Escalera Briceño, Alejandro, Ángeles Villa, Manuel y Palafox Muñoz, Alejandro (20I8). Los Límites de la Economía Ecológica en la Era del Capitaloceno. Revista de Ciencias Sociales, Universidad de Costa Rica, I60, I37-I5I. 
Estenssoro, Fernando (2019). La Geopolítica Ambiental Global del Siglo XXI. Los desafíos para América Latina. RIL editores.

Estenssoro, Fernando (2020). Historia del Debate Ambiental en la Política Mundial 1945-1992. La perspectiva latinoamericana (Nueva edición corregida y aumentada). Biblos.

Ellis, Erle C. (2018). Antrhopocene. A very short introduction. Oxford University Press.

García Acosta, Virginia (2017). La incursión del Antropoceno en el sur del Planeta. Desacatos, 54, 815 .

Haraway, Donna J. (2016). Staying with the trouble: Anthropocene, Capitalocnene, Chthulucene. En Moore, Jason W. (Ed.), Anthropocene or Capitalocene? Nature, History and the Crisis of Capitalism (pp. 34-76). Kairos-PM Press.

Hartley, Daniel (2016). Anthropocene, Capitalocene, and the Problem of Culture. En Moore, Jason W. (Ed.), Anthropocene or Capitalocene? Nature, History and the Crisis of Capitalism (pp. I54165). Kairos-PM Press.

Huttunen, Suvi, Skytén, Emmi y Hildén, Mikael (2015). Emerging policy perspectives on geoengineering: An international comparison. The Anthropocene Review, 2(I), I4-32.

Kintisch, Eli (2013). Manipular el clima: ¿locura o necesidad?. MIT Techonology Review. hetps://cutt.ly/QTpW6ZG

Latour, Bruno (2017). Facing Gaia. Eight Lectures on the New Climatic Regime. Polity Press.

Lewis, Simon L. y Maslin, Mark A. (2018). The Human Planet. How we created the Anthropocene. Penguin Books.

Manrique, Luis Esteban G. (2015). El Antropoceno: la era de la depredación. Política Exterior, $29(\mathrm{I} 65), \mathrm{170}-\mathrm{I} 74$.

McBrien, Justin; (2016). Accumulating Extinction: Planetary Catastrophism in the Necrocene. En Moore, Jason W. (Ed.), Anthropocene or Capitalocene? Nature, History and the Crisis of Capitalism (pp. Iı6-г37). Kairos-PM Press.

Moore, Jason W. (2003). Nature and the Transition from Feudalism to Capitalism. Review: A Journal of the Fernand Braudel Center, 26(2), 97-172 
Moore, Jason W. (2007). The Capitalocene, Part I: on the nature and origins of our ecological crisis. The Journal of Peasant Studies, 43, 594-630.

Moore, Jason W. (20rza). El auge de la ecología-mundo capitalista. Las fronteras mercantiles en el auge y decadencia de la apropiación máxima. Laberinto, 38, 10-26

Moore, Jason W. (2013b). Feudalismo, Capitalismo, Socialismo, o Teoría y Política de las Transiciones Eco-históricas. Laberinto, 40, 31-37.

Moore, Jason W. (2016). The Rise of Cheap Nature. En Moore, Jason. W (Ed.), Anthropocene or Capitalocene? Nature, History, and the Crisis of Capitalism (pp. 78-II5). Kairos-PM Press.

Moore, Jason W. (2017a). El fin de la naturaleza barata: o cómo aprendí a dejar de preocuparme por "el" medioambiente y amar la crisis del capitalismo. Relaciones Internacionales, 33, I43-174.

Moore, Jason W. (2017b). The Capitalocene, Part I: on the nature and origins of our ecological crisis. The Journal of Peasant Studies, 44, 594-630.

Naciones Unidas (1973). Informe de la Conferencia de las Naciones Unidas sobre el Medio Humano. Naciones Unidas. https://cutt.ly/ITpErgp

Parenti, Christian (2016). Environment-Making in the Capitalocene: Polítical Ecology oh the State". En Moore, Jason W. (Ed.), Anthropocene or Capitalocene? Nature, History and the Crisis of Capitalism (pp. 166-184). Kairos-PM Press.

Ulloa, Astrid (2017). Dinámicas ambientales y extractivas en el siglo XXI: ¿es la época del Antropoceno o del Capitaloceno en Latinoamérica? Desacatos, 54, 58-73.

Sánchez León, Nuria (2019). Arte Transicional para el Capitaloceno. Arte y Políticas de Identidad, 20, $82-96$.

Steffen, Will, Grinevald, Jacques, Crutzen, Paul y Mcneill, John (20II). The Anthropocene: conceptual and historical perspectives. Philosophical Transactions of the Royal Society A, 369, $842-867$.

Steffen, Will, Crutzen, Paul J. y McNeill, John R. (2007). The Anthropocene: Are Humans Now Overwhelming the Great Forces of Nature? Ambio, 36(8), 6I4-62I. 
Svampa, Maristella (2019). El Antropoceno como diagnóstico y paradigma. Lecturas globales desde el Sur. Estudios, 84, 33-54.

Thrischler, Helmuth (2017). El Antropoceno, ¿un concepto geológico o cultural, o ambos? Desacatos, $54,40-57$.

Ward, Barbara y Dubos, Réne (1984). Una Sola Tierra. El cuidado y conservación de un pequeño planeta. Fondo de Cultura Económica.

Zalasiewicz, Jan, Williams, Mark, Smith, Alan, Barry, Tiffany L., Coe, Angela L., Brown, Paul L., Brenchley, Patrick, Cantrill, David, Gale, Andrew, Gibbard, Philip, Gregory, F. John, Hounslow, Mark W., Kerr, Andrew C., Pearson, Paul, Knox, Robert, Powell, John, Waters, Colin, Marshall, John, Oates, Michael, Rawson, Peter y Stone, Philip (2008). Are we now living in the Anthropocene? GSA Today, I8(2), 4-8. 